\title{
Reproductive Dysfunction from the Stress of Exercise Training is not Gender Specific: The "Exercise-Hypogonadal Male Condition"
}

\author{
Amy R. Lane ${ }^{1}$ and Anthony C. Hackney ${ }^{1,2,3 *}$ \\ ${ }^{1}$ Human Movement Science Curriculum, University of North Carolina - Chapel Hill, NC, USA \\ ${ }^{2}$ Department of Exercise \& Sport Science, University of North Carolina - Chapel Hill, NC, USA \\ ${ }^{3}$ Department of Nutrition - Gillings School of Global Public Health, University of North Carolina - Chapel Hill, NC, USA
}

Received: April 17, 2014 ; Accepted: May 12, 2014; Published: May 30, 2014

*Corresponding author: A.C. Hackney, Endocrine Section - Applied Physiology Laboratory, 203 Fetzer Hall - South Road, University of North Carolina, Chapel Hill, North Carolina, 27599-8700, USA, Tel: 919-962-0334; Fax: 919-962-0489: E-mail: ach@email.unc.edu

\begin{abstract}
Investigative studies point to participation in exercise training as having significant detrimental effects upon reproductive hormonal profiles in men. Specifically, men chronically exposed to training for endurance sports exhibit persistently reduced basal (restingstate) free and total testosterone concentrations without concurrent LH elevations. Men displaying these symptoms have been deemed to exhibit the "Exercise-Hypogonadal Male Condition" (EHMC). The exact physiological mechanism inducing the reduction of testosterone in these men is currently unclear, but is postulated to be a dysfunction within the hypothalamic-pituitary-gonadal regulatory axis. The potential exists for the reduced testosterone concentrations within EHMC men to be disruptive and detrimental to some anabolicandrogenic testosterone-dependent physiological processes. Findings, while limited, suggest spermatogenesis problems may exist in some cases; thus, infertility risk in such men is a critical concern. Present evidence suggests the EHMC condition is limited to men who have been persistently involved in chronic endurance exercise training for an extended period of time, and thus is not a highly prevalent occurrence. Nevertheless, it is critical that endocrinologist and fertility clinicians become more aware of the existence of EHMC as a potential problem-diagnosis in their male patients who exercise.
\end{abstract}

\section{Introduction}

For over 30 years it has been known that women who engage in large amounts of exercise without proper nutrition are at increased risk for development of reproductive dysfunctions [1-3]. Specifically they are susceptible to development of oligomenorrhea or secondary amenorrhea ("Athletic Amenorrhea") and osteopenia [1,2]. These conditions are associated with varying degrees of reproductive hormonal abnormalities (i.e., hypoestrogenism) and risk for infertility [1,2]. Until recently scientists thought these resultant exercise-related reproductive dysfunctions were gender specific - affecting only women. Within the last two decades, however, substantial evidence has mounted to support that men are also susceptible to exercise-related reproductive dysfunctions. Specifically, development of what is termed the "Exercise-Hypogonadal Male Condition" (EHMC) [4-6]. This review provides an overview commentary on the EHMC symptomology and the key findings supporting the existence of the condition.

\section{Background}

Retrospective, cross-sectional comparative studies examining resting blood samples indicate lower circulating testosterone levels exist in chronically exercise-trained male athletes specifically those who participate in endurance sporting activities; such as, marathon distance running, long-course triathlons, and Olympic distance race walking [5-9]. The evidence in these studies is decidedly convincing. The subjects in these studies have typically been athletes-exercisers who had been chronically involved with the exercise training aspects of their sport for a number of years (i.e., $\geq 10-15$ ) [10-15]. These studies report the testosterone levels (free and total concentrations) of these men to be only $50-85 \%$ of the levels of comparable agematched, non-exercising men [10-17].

Prospective studies in which resting blood samples have been collected over days, weeks or months while exposing subjects to strenuous endurance training regimens also reveal testosterone levels become lower. However, the findings from these prospective studies are somewhat inconsistent and not as compelling as the retrospective studies[7,18-21].Differences in the initial training status of the subjects or the specifics of the training program administered within these prospective studies may explain these discrepancies $[6,16]$. Currently there is a need for more extensive and longer term prospective studies to address the inconsistent findings; however, such studies are extremely time-consuming, expensive and challenging to the investigators.

Endurance-trained males with lower testosterone also frequently display other reproductive hormonal abnormalities. The most prevalent being changes involving altered $(\uparrow \downarrow)$ resting 
levels of prolactin and more importantly, a lack of an appropriate change in resting luteinizing hormone (LH) concentration or pulsatile characteristics [13], even though decreased testosterone levels exist $[13,22,23]$. Some evidence points to these LH findings being related to disruption of hypothalamic gonadotropinreleasing hormone $(\mathrm{GnRH})$ secretion [13]; as is seen in many women with exercise-related reproductive dysfunctions [1,2]. Such occurrences for LH and GnRH are thought to be indicative of a dysfunction in the hypothalamic-pituitary-gonadal (HPG; male -testicular; female - ovarian) regulatory axis for the male-female reproductive systems $[8,24]$.

If one considers the gender specific aspects of the reproductive endocrine system, the lowered resting testosterone in these male athletes is analogous to the lower estrogen-progesterone levels found in female athletes with exercise-related reproductive dysfunctions [25-30]. Furthermore, as noted, the HPG axis disruption denoted from the non-appropriate $\mathrm{LH}-\mathrm{GnRH}$ response within EHMC men is also found in some women with athletic amenorrhea [1,26].

\section{Mechanisms of Hypothalamic-Pituitary-Gonadal Axis Dysfunction with EHMC}

Studies attempting to elucidate the mechanism of the HPG axis dysfunction in EHMC men have centered on determining whether the dysfunction is of a central (hypothalamic-pituitary) or a peripheral (testicular) endocrine origin. Centrally, studies have focused on LH and/or prolactin (PRL) glandular release, while testosterone release has been the target of peripheral studies. Alterations in LH-PRL have been extensively studied relative to exercising women who develop reproductive dysfunctions $[1,13,31,32]$, hence aspects of the male related work are modeled in accordance with that in females.

An exaggerated PRL release to endogenous or exogenous anterior pituitary stimuli occurs in EHMC men [33-35]. Furthermore, an attenuated release of LH due to similar endogenous or exogenous stimuli also occurs in EHMC men [33]. Again, comparable outcomes have been reported in athletic women who have reproductive dysfunctions such as oligomenorrhea or athletic amenorrhea [31,32]. Although it is important to note that not all of the reproductive hormonal changes seen in exercising men and women are in complete agreement, as gender differences in aspects of the HPG axis do exist. Furthermore, the type and nature of the protocols used within research studies as well as demographics of the male and female research subjects has led to some variability in the findings.

Peripheral mechanistic studies have shown EHMC men have a reduced testosterone response to an exogenous stimulus $[33,36]$. When compared to match-control sedentary men there is a $15-40 \%$ blunting of the testicular response at a given relative stimulus dosage level. It is currently unclear if this attenuated response is the result of reduced glandular receptor sensitivityresponsiveness or "down-stream" events involving a disruption in the steroidogenic process for testosterone synthesis [6].

\section{Physiological Impact of Lower Testosterone}

Evidence suggests that the development of low resting testosterone in EHMC men has some detrimental effects on the testosterone-dependent physiological processes of the body; although at present, this work is limited in scope and quantity and additional studies are needed.

For example, there are some findings of decreased spermatogenesis or oligospermic conditions existing in EHMC men [16,37-39]. Additionally, some investigators have also reported endurance-exercise trained men may have a lowered sex drive; but, these findings are primarily anecdotal in nature and more work is necessary in this behavioral related topic $[6,40,41]$. Disruption of sperm production in the EHMC male certainly increases the risk of fertility problems in these men; and several investigators have indicated the strong correlate of such findings to the infertility issues typically associated with athletic amenorrhea in women $[1,2,6,8,41]$.

Research of the detrimental effects of lower testosterone on other anabolic-androgenic processes of testosterone such as protein synthesis and muscle mass development is extremely limited and inconclusive. Although, it has been postulated that the lower testosterone found in these men allows for a lower overall muscle mass; which could be useful in participation in endurance-based sports ( $\downarrow$ mass $\Rightarrow \downarrow$ oxygen requirement to perform the sporting event and hence $\downarrow$ energy expenditure) [7,42]. An area in need of further research concerns bone demineralization, low testosterone and osteopenia in EHMC men. Clinically, there is strong evidence indicating hypogonadal and hypo-testosteronemic men can have severe mineral loss from their bones [43-46]. Thus far, there are no conclusive large scale study findings of substantial negative mineral content change in EHMC men with low testosterone, but several compelling case studies have been reported in the literature $[47,48]$. This appears to be an aspect of the male and female comparison which is not completely analogous between the sexes based upon current evidence.

\section{Conclusions}

Exercise-training, specifically that which is associated with endurance sporting activities has significant negative effects upon the major male reproductive hormone (testosterone $\downarrow$ ) as well as the other reproductive hormones (LH and PRL). This reproductive endocrine status has been termed the "ExerciseHypogonadal Male Condition" [4-6]. The mechanism of this lowering is currently unclear, but may be related to a HPG axis dysfunction brought about by years of chronic exposure to the physical stress of endurance-exercise training. Furthermore, findings indicate that such training disrupts some aspect of testosterone-dependent anabolic or androgenic processes in EHMC men. It is important to recognize, however, that the prevalence of EHMC seems somewhat low relative to entire population of male endurance athletes (estimates are approximately 15\%) [49]. This seems due to that fact that only a small percentage of such athletes stay engaged with their exercise 
and sporting activity long enough, and consistently enough, to manifest the symptomology.

Nonetheless, it is recommended that clinicians and endocrinologists become more aware of the existence of this condition. This seems highly pertinent since evidence supports that clinicians may need to consider utilizing steps within their practices to assess and perhaps treat the occurrence of EHMC, especially relative to issues surrounding potential male infertility concerns.

\section{References}

1. Loucks AB, Redman LM (2004) The effect of stress on menstrual function. Trends Endocrinol Metab. 15(10): 466-471.

2. Dusek T (2001) Influence of high intensity training on menstrual cycle disorders in athletes. Croat Med J. 42(1): 79-82.

3. Galbo H (1983) Hormonal and metabolic adaptations to exercise. Thieme-Stratton Inc New York, Usa.

4. Hackney AC, Hackney ZC (2005) The exercise-hypogonadal male condition and endurance exercise training. Curr Trends Endocinol 1: 101-106.

5. Hackney AC, Moore AW, Brownlee KK (2005) Testosterone and endurance exercise: development of the "exercise-hypogonadal male condition”. Acta Physiol Hung. 92(2): 121-137.

6. Hackney AC (2008) Effects of endurance exercise on the reproductive system of men: the "exercise-hypogonadal male condition". J Endocrino Invest. 31(10): 932-938.

7. Hackney AC (1996) Testosterone the hypothalamo-pituitarytesticular axis and endurance exercise training: a review. Biol Sport 13(2): 85-98.

8. Hackney AC (1989) Endurance training and testosterone levels. Sports Med. 8(2): 117-127.

9. Hackney AC (1996) The male reproductive system and endurance exercise. Med Sci Sports Exerc. 28(2): 180-189.

10. Hackney AC, Dolny DG, Ness RJ (1988) Comparison of resting reproductive hormonal profiles in select athletic groups. Biol Sport. 4(5): 297-304

11. Gulledge TP, Hackney AC (1996) Reproducibility of low testosterone concentrations in endurance trained men. Eur J Appl Physiol Occup Physiol. 73(6): 582-583.

12. Hackney AC, Sinning WE, Bruot BC (1988) Reproductive hormonal profiles of endurance-trained and untrained males. Med Sci Sports Exerc. 20(1): 60-65

13. MacConnie SE, Barkan A, Lampman RM, Schork MA, Beitins IZ (1986) Decreased hypothalamic gonadotrophin-releasing hormone secretion in male marathon runners. N Engl J Med. 315(7): 411-417.

14. Hackney AC, Fahrner CL, Gulledge TP (1998) Basal reproductive hormonal profiles are altered in endurance trained men. J Sports Med Phys Fitness. 38(2): 138-141.

15. Ayers JWT, Komesu V, Romani T, Ansbacher R (1985) Anthropomorphic, hormonal, and psychologic correlates of semen quality in endurancetrained male athletes. Fertil Steril. 43(6): 917-921.

16. Arce JC, De Souza MJ (1993) Exercise and male factor infertility. Sports Med. 15(3): 146-169.

17. Wheeler GD, Wall SR, Belcastro AN, Cumming DC (1984)Reduced serum testosterone and prolactin levels in male distance runners.JAMA. 252(4): 514-516.

18. Hackney AC, Sharp RL, Runyan WS, Ness RJ (1989) Relationship of resting prolactin and testosterone in males during intensive training.Br J Sports Med. 23(3): 194

19. Urhausen A, Kullmer T, Kindermann W (1987) A 7-week follow-up study of the behaviour of testosterone and cortisol during the competition period in rowers. Eur J Appl Physiol Occup Physiol. 56(5): 528-533.

20. Lane AR, Duke JW, Hackney AC (2010) Influence of dietary carbohydrate intake on the free testosterone: cortisol ratio responses to short-term intensive exercise training. Eur J Appl Physiol. 108(6): 1125-1131.

21. Vervoorn C, Quist AM, Vermulst LJ, Erich WB, de Vries WR et al. (1991) The behaviour of the plasma free testosterone/cortisol ratio during a season of elite rowing training. Int J Sports Med. 12(3): 257-263.

22. McColl EM, Wheeler GD, Gomes P, Bhambhani Y, Cumming DC (1989) The effects of acute exercise on pulsatile LH release in high-mileage male runners. Clin Endocrinol (Oxf). 31(5): 617-621.

23. Wheeler GD, Singh M, Pierce WD, Epling WF, Cumming DC (1991) Endurance training decreases serum testosterone levels in men without change in luteinizing hormone pulsatile release. J Clin Endocrinol Metab. 72(2): 422-425.

24. Cumming DC, Wheeler GD, McColl EM (1989) The effects of exercise on reproductive function in men. Sports Med. 7(1): 1-17.

25. Bunt JC, Bahr JM, Bemben DA (1987) Comparison of estradiol and testosterone levels during and immediately following prolonged exercise in moderately active and trained males and females. Endocr Res. 13(2): $157-172$.

26. Berga SL, Mortola JF, Girton L, Suh B, Laughlin G et al. (1989) Neuroendocrine aberrations in women with functional hypothalamic amenorrhea. J Clin Endocrinol Metab. 68(2): 301-308.

27. Williams NI, Caston-Balderrama AL, Helmreich DL, Parfitt DB, Nosbisch C et al. (2001) Longitudinal changes in reproductive hormones and menstrual cyclicity in cynomolgus monkeys during strenuous exercise training: abrupt transition to exercise-induced amenorrhea. Endocrinology. 142(6): 2381-2389.

28. De Souza MJ, van Heest J, Demers LM, Lasley BL (2003) Luteal phase deficiency in recreational runners: evidence for hypometabolic state. J Clin Endocrinol Metab. 88(1): 337-346.

29. De Souza MJ, Miller BE, Loucks AB, Luciano AA, Pescatello LS (1998) High frequency of luteal phase deficiency and anovulation in recreational women runners: blunted elevation in follicle-stimulating hormone observed during luteal-follicular transition. J Clin Endocrinol Metab. 83(12): 4220-4232.

30. Cumming DC, Vickovic MM, Wall SR, Fluker MR (1985) Defects in pulsatile LH release in normally menstruating runners. J Clin Endocrinol Metab. 60(4): 810-812.

31. Boyden TW, Pamenter RW, Grosso D, Stanforth P, Rotkis T et al. (1982) Prolactin responses, menstrual cycles, and body composition of women runners. J Clin Endocrinol Metab. 54(4): 711-714.

32. Boyden TW, Pamenter RW, Stanforth PR, Rotkis TC, Wilmore JH (1984) Impaired gonadotropin responses to gonadotropin-releasing hormone stimulation in endurance-trained women. Fertil Steril. 41(3): 359-363.

33. Hackney AC, Sinning WE, Bruot BC (1990) Hypothalamic-pituitarytesticular axis function of endurance-trained males. Int J Sports Med. 11(4): 298-303 
34. Hackney AC, Fahrner CL, Stupnicki R (1997) Reproductive hormonal responses to maximal exercise in endurance-trained men with low resting testosterone levels. Exp Clin Endocrinol Diabetes. 105(5): 291-295.

35. Daly W, Seegers CA, Rubin DA, Dobridge JD, Hackney AC (2005) Relationship between stress hormones and testosterone with prolonged endurance exercise. Eur J Appl Physiol. 93(4): 375-380.

36. Hackney AC, Szczepanowska E, Viru AM (2003) Basal testicular testosterone production in endurance-trained men is suppressed. Eur J Appl Physiol. 89(2): 198-201.

37. Miller B, Hackney AC, DeSouza MJ (1997) The effect of endurance training on hormone and semen profiles in marathon runners: comments. Fertil Steril 67(3): 585-587.

38. Brant WO, Myers JB, Carrell DT, Smith JF (2010) Male athletic activities and their effects on semen and hormonal parameters. Phys Sportsmed. 38(3): 114-120.

39. Wise LA, Cramer DW, Hornstein MD, Ashby RK, Missmer SA (2011) Physical activity and semen quality among men attending an infertility clinic. Fertil Steril. 95(3): 1025-1030.

40. Skarda ST,Burge MR (1998) Prospective evaluation of risk factors for exercise-induced hypogonadism in male runners. West J Med. 169(1): 9-12.

41. Di Luigi L, Romanelli F, Sgro P, Lenzi A (2012) Andrological aspects of physical exercise and sport medicine. Endocrine. 42(2): 278-284

42. Bribiescas RG (1996) Testosterone levels among Aché hunter-gatherer men. Hum Nat 7(2): 163-188.

43. Behre HM, Kliesch S, Leifke E, Link TM, Nieschlag E (1997) Long-term effect of testosterone therapy on bone mineral density in hypogonadal men. J Clin Endocrinol Metab. 82(8): 2386-2390.

44. Riggs BL, Eastell R (1986) Exercise, hypogonadism, and osteopenia. JAMA. 256(3): 392-393.

45. Rigotti NA, Neer RM, Jameson L. (1986) Osteopenia and bone fractures in a man with anorexia nervosa and hypogonadism. JAMA. 256(3): 385-388.

46. Hetland ML, Haarbo J, Christiansen C (1993) Low bone mass and high bone turnover in male long distance runners. J Clin Endocrinol Metab. 77(3): 770-775.

47. MacDougall JD, Webber CE, Martin J, Ormerod S, Chesley A et al. (1992) Relationship among running mileage, bone density, and serum testosterone in male runners. J Appl Physiol. 73(3): 1165-1170.

48. Maïmoun L, Lumbroso S, Manetta J, Paris F, Leroux JL (2003) Testosterone is significantly reduced in endurance athletes without impact on bone mineral density. Horm Res. 59(6): 285-292.

49. Hackney AC (2013) Endócrino desregulação associados com o treinamento físico. Discurso de abertura. II Conferência Internacional de Esporte e Saúde. Centro Universitario de Brasilia. Brasilia, Brasil. 